\title{
In Vitro Evaluation of Ferrule Effect and Depth of Post Insertion on Fracture Resistance of Fiber Posts
}

\author{
R. Schiavetti and G. Sannino \\ Department of Oral Health, University of Rome Tor Vergata, Viale Oxford, 00100 Rome, Italy \\ Correspondence should be addressed to G. Sannino, gianpaolo.sannino@uniroma2.it
}

Received 10 October 2012; Accepted 5 November 2012

Academic Editor: Carlo Cattani

Copyright ( $\odot 2012$ R. Schiavetti and G. Sannino. This is an open access article distributed under the Creative Commons Attribution License, which permits unrestricted use, distribution, and reproduction in any medium, provided the original work is properly cited.

\begin{abstract}
Purpose. The analysis of the complex model of fiber post and ferrule is given and studied in this paper. A novel approach and a solution to the evaluation of stress of post and core system within the ferrule effect are proposed. Methods. Sixty freshly extracted premolars were selected for the study. The following experimental groups were therefore defined $(n=10):(1) 5 \mathrm{~mm},(2) 7 \mathrm{~mm},(3)$ $9 \mathrm{~mm}$, (4) ferrule- $5 \mathrm{~mm}$, (5) ferrule-7 mm, and (6) ferrule- $9 \mathrm{~mm}$. Preshaping drills (C) were used to prepare the root canals at 5 , 7 , and $9 \mathrm{~mm}$ in depth. In specimens of groups 3-6 a circumferential collar of tooth structure of $2 \mathrm{~mm}$ in height. Fluorocore 2 core build-up material (I) was used for fiber post luting. With the same material, a buildup of $2 \mathrm{~mm}$ in height was created. A controlled compressive load (crosshead speed: $0.75 \mathrm{~mm} / \mathrm{min}$ ) was applied by means of a stainless steel stylus ( $\varnothing 1 \mathrm{~mm}$ ) at the coronal end of the post extruding out of the root. Results. In all the tests the level of significance was set at $P<0.05$. Significantly higher fracture strengths were measured in the presence of a ferrule effect. In groups 1, 2, and 3 (ferrule group), the mean fracture values were, respectively, $163,8 \mathrm{~N}, 270,9 \mathrm{~N}$, and $254,7 \mathrm{~N}$. These data are higher and statistically significantly different when compared with the three groups 4, 5, and 6 (no-ferrule group), in which the values obtained were, respectively, 40,5 N, 41,7 N, and 44,9 N. Conclusion. The ferrule effect in the endodontically treated teeth positively affects the fracture strength of the fiber post. Conversely, post depth insertion did not affect the resistance to fracture.
\end{abstract}

\section{Introduction}

A persistent problem in clinical dentistry is represented by the risk fracture of endodontically treated teeth [1]. These teeth are considered to be less resistance, because of the loss of tooth structure during conservative access cavity preparation. The influence of subsequent canal instrumentation and obturation leads to a reduction in the resistance to fracture $[2,3]$. To restore these teeth, posts are often required in order to provide anchorage for the core-forming material and coronoradicular stabilization $[4,5]$. Cast posts and cores have been used for this purpose for many years, while more recently fiber posts showed to represent a valid alternative. The clinical success of fiber post restorations is mainly related to their biomechanical properties that, being close to those of dentin, reduce stress transmission to the roots [6-9]. The potential of fiber posts to reduce the incidence of nonretrievable root fractures in comparison with cast posts was confirmed in several studies [10-12]. Among the several parameters influencing the success of a post-based rehabilitation, preservation of coronal dental tissue and, particularly, the presence of a ferrule effect have been advocated as favorable conditions to decrease stress transmission to the root [13]. Sorensen and Engelman [14] described the ferrule as the coronal-dentinal extension of the tooth structure occlusal to the shoulder preparation. The ferrule effect in association with cast post and cores has been studied by many investigators [15-17]. Conversely, little information is available if the ferrule is of additional value in providing reinforcement in teeth restored with prefabricated post and composite cores, and the advantages coming from the presence of ferrule in prefabricated post and core are questioned by Al-Hazaimeh and Gutteridge [18].

The main task of this in vitro study is to evaluate the effect of ferrule preparation on fracture resistance of fiber 
post, as a function of the presence/absence of a ferrule and as a function of the depth of insertion of the fiber posts.

The formulated null hypothesis was that neither depth of post insertion nor the presence of a $2 \mathrm{~mm}$ high ferrule had a significant influence on fracture resistance of a fiber postretained restoration.

\section{Material and Methods}

Sixty freshly extracted premolars were selected for the study. Teeth had to be free of cracks, caries, and fractures and were stored at room temperature in saline solution before testing. The anatomic crowns of all teeth were sectioned perpendicularly to the tooth long axis at the cement-enamel junction (CEJ). Roots were endodontically treated using the "step-back" technique [19] to a number 70 size file (A) (see Table 2 ) and irrigated with $2.5 \%$ sodium hypochlorite.

Each canal was obturated using the lateral condensation technique with gutta-percha points (B) and the resin sealer AH Plus Jet (C) (see Table 2). The endodontic access cavities were temporarily filled with a glass ionomer cement (D) (Fuji II, GC corp, Tokyo, Japan). After 24 hours, the coronal seal was removed by means of 240-grit abrasive SiC papers under water cooling. Roots were randomly divided into six experimental groups that differed for the depth of the prepared post space and for the presence or absence of a ferrule effect. The following experimental groups were therefore defined $(n=10)$ : (1) $5 \mathrm{~mm}$ (Figure 1(a)); (2) $7 \mathrm{~mm}$ (Figure 1(b)); (3) $9 \mathrm{~mm}$ (Figure 1(c)); (4) ferrule$5 \mathrm{~mm}$ (Figure 1(d)); (5) ferrule-7 mm (Figure 1(e)); (6) ferrule-9 mm (Figure 1(f)). Preshaping drills (C) were used to prepare the root canals at 5,7 , and $9 \mathrm{~mm}$ in depth. After preparation, it was checked that a $3-\mathrm{mm}$ long gutta-percha apical seal. In specimens of groups 3-6 a circumferential collar of tooth structure of $2 \mathrm{~mm}$ in height and $3 \mathrm{~mm}$ in width was realized with a diamond bur (Figure 2).

Translucent quartz fiber posts (E) consisting of unidirectional, pretensed fibers bound in a translucent epoxy resin matrix, were used. Each post was tried in into the root canal, and the portion of the post extruding out the root was cut to a standardized length of 4.8 [20]. Prior to cementation, a prehydrolyzed silane coupling agent $(\mathrm{F})$ was applied with a microbrush on the post surface for $30 \mathrm{~s}$. The light cured, selfpriming adhesive Prime and Bond NT (G) was applied into the root canal with a microbrush for $20 \mathrm{~s}$ and gently air-dried. The excess was removed using paper points. The bonding agent was polymerized with a conventional quartz-tungstenhalogen light $\left(750 \mathrm{~mW} / \mathrm{cm}^{2}\right)(\mathrm{H})$. Fluorocore 2 core buildup material (I) was used for fiber post luting. Base and catalyst $(1: 1)$ were mixed for $30 \mathrm{~s}$, then the material was applied on the post. The post was seated immediately into the canal and sustained under finger pressure. With the same material, a buildup of $2 \mathrm{~mm}$ in height was created. After the first 7-minute autocure period, the material was light-cured for $40 \mathrm{~s}$. After curing, the specimens were prepared as for a prosthetic crown, with a circumferential chamfer reduction of $1,5 \mathrm{~mm}$ of maximum thickness, using a chamfer bur of $2 \mathrm{~mm}$ in diameter $(\mathrm{M})$. After post cementation, each root was embedded in a self-polymerizing acrylic resin $(\mathrm{J})$ for half of the root length, with the long axis sloped at a 45-degree angle to the base of the resin block. During this procedure, specimens were continuously irrigated with water to avoid overheating due to resin polymerization. Before performing the mechanical test, samples were stored for 24 hours at $37^{\circ} \mathrm{C}$ and $100 \%$ relative humidity.

Each sample was then mounted on a universal testing machine $(\mathrm{K})$. A controlled compressive load (cross-head speed: $0.75 \mathrm{~mm} / \mathrm{min}$ ) was applied by means of a stainless steel stylus ( $\varnothing 1 \mathrm{~mm}$ ) at the coronal end of the post extruding out of the root (Figure 3). A software (L) connected to the loading machine recorded the load at failure of the postretained restoration measured in Newton $(\mathrm{N})$.

\section{Results}

Descriptive statistics of fracture strength data are reported in Table 1, along with the significance of between-group differences. As the distribution of fracture strengths was not normal according to the Kolmogorov-Smirnov test, the use of the Two-Way Analysis of Variance to assess the influence of depth, ferrule effect, and between-factor interaction was precluded. Therefore, the Kruskal-Wallis One-Way Analysis of Variance was applied with strength as the dependent variable and experimental group as factor. Consequently, the Dunn's multiple range test was used for post hoc comparisons. In all the tests the level of significance was set at $P<0.05$. Significantly higher fracture strengths were measured in the presence of a ferrule effect. Neither in the presence or in the absence of a ferrule effect had depth of post insertion a significant influence on fracture strength, as no statistically significant differences emerged either among groups $1-3$ or among groups $4-6$.

The results obtained from this in vitro study showed a correlation between the presence of the ferrule and increased resistance to fracture. In groups 1, 2, and 3 (with ferrule), the mean fracture values were, respectively, $163,8 \mathrm{~N}, 270,9 \mathrm{~N}$ and $254,7 \mathrm{~N}$. These data are higher and statistically significantly different when compared with the three groups 4, 5, and 6 , without ferrule effect, in which the values obtained were, respectively, 40,5 N, 41,7 N, and 44,9 N.

The depth of post insertion did not show to be a parameter affecting the results. In fact, no statistically significant differences were found between groups 1, 2, and 3 as well as between groups 4,5 , and 6 .

\section{Discussion}

Since in the presence of a ferrule, significantly higher fracture strengths were measured, the null hypothesis has to be rejected.

Several factors determine the performances and the success of a rehabilitation clinic in time: types, design, and lengths of post, bonding capacity [21], and ferrule. Large variations exist in regard to the physical and fatigue resistance of resin-fiber posts [22]. The static or dynamic behavior of resin-fiber posts depends on the composition 
TABLe 1: Descriptive statistics of fiber post fracture strength data with the significance of between-group differences.

\begin{tabular}{lccccccc}
\hline Number group & Name group & $N$ & Mean & Std. Deviation & Median & $25 \%-75 \%$ & Significance $P<0.05$ \\
\hline 1 & Ferrule-5 mm & 10 & 163,8 & 72,5 & 142,9 & $132,7-181,1$ & AB \\
2 & Ferrule-7 mm & 10 & 270,9 & 105,6 & 244,9 & $215,2-350,3$ & A \\
3 & Ferrule-9 mm & 10 & 254,7 & 79,1 & 235,4 & $193,4-305,6$ & A \\
4 & No ferrule-5 mm & 10 & 40,5 & 3,1 & 40,2 & $38,4-44,2$ & C \\
5 & No ferrule-7 mm & 10 & 41,7 & 5,3 & 43 & $36,8-46,2$ & C \\
6 & No ferrule-9 mm & 10 & 44,9 & 6,7 & 44,5 & $40,5-51,7$ & BC \\
\hline
\end{tabular}

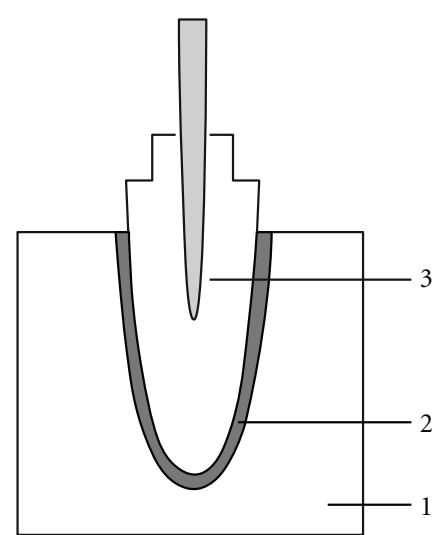

(a)

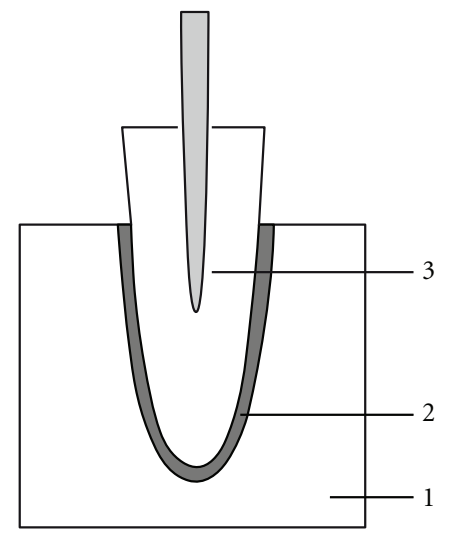

(d)

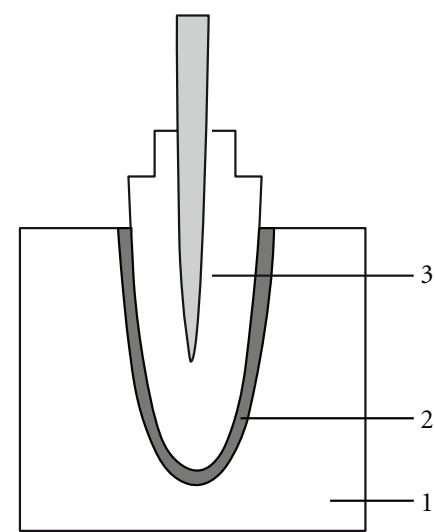

(b)

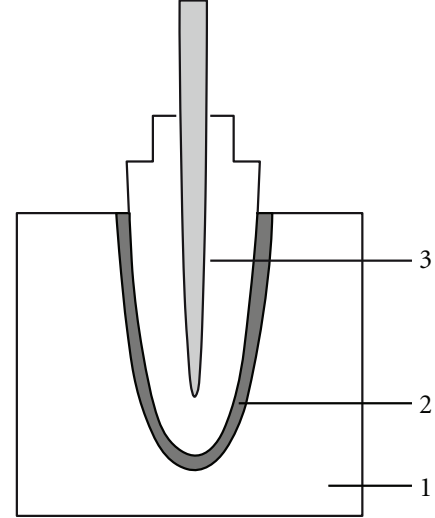

(c)

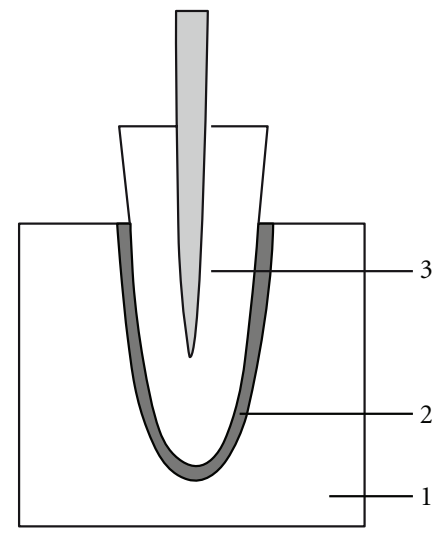

(e)

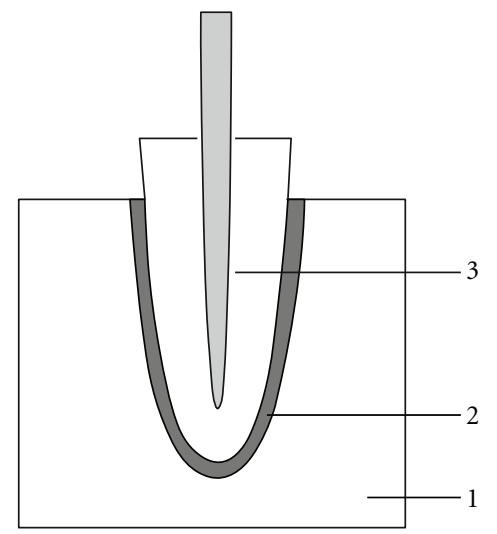

(f)

FIGURE 1: Experimental groups with different post depth $(5,7$, and $9 \mathrm{~mm}$ ) and postspace with (groups a, b, c) and without (groups d, e, f) a ferrule effect.

(fiber type and density) as well as the fabrication process and, in particular, the quality of the resin-fiber interface. In an in vitro study examining physical properties of various posts, it was concluded that the ideal post design comprises a cylindrical coronal portion and a conical apical portion [23]. Much discussed is still the ideal post length, if one part provides greater stability to prosthetic rehabilitation at the same time involves removal of dentin [24] and more because of the existing limitations of adhesive procedures within the root canal [25-27]. It has been demonstrated that the loss of tooth vitality is not accompanied by significant change in tissue moisture or collagen structure [28-30]. The most important changes in tooth biomechanics are attributed to the loss of tissue either at radicular $[2,31]$ or coronal [31-34] levels, pointing out the importance of a highly conservative approach during endodontic and restorative procedures. The significance of remaining cervical tissue, known as the ferrule, was also well documented $[13,35]$. The incorporation of a ferrule is an important factor of tooth preparation when using a post-supported rehabilitation technique [36-38]. The effectiveness of the ferrule has been evaluated with several laboratory tests as fracture resistance, such as [39] impact [40], fatigue [41], and photoelastic analysis [42]. According to these studies the ferrule presence showed values of resistance to fracture much higher and statistically significant differences in groups 1,2 , and 3 than no-ferrule groups (groups 4, 5, 6). Concerning the length of the ferrule, some studies have reported that 
TABLE 2: Classification of instruments used for collecting and measuring data during the tests.

\begin{tabular}{ll}
\hline Class & Type \\
\hline (A) & Flex R File, Union Broach, York, PA, USA \\
(B) & Dentsply, Maillefer, Tulsa, OK, USA \\
(C) & DeTrey, Konstanz, Germany \\
(D) & Fuji II, Gc corp, Tokyo, Japan \\
(E) & ENDO LIGHT-POST number 3 Bisco, Schaumburg, \\
(F) & IL, USA \\
(G) & Prime and Bond NT Dentsply DeTrey, Konstanz, \\
(H) & Opermany \\
(I) & Fluorocore 2 Dentsply DeTrey, Konstanz, Germany \\
(J) & ProBase Cold Ivoclar Vivadent, Schaan Fürstentum, \\
(K) & Liechtenstein \\
(L) & Digimax Plus Controls srl, Cernusco s/n, Italy \\
\hline
\end{tabular}

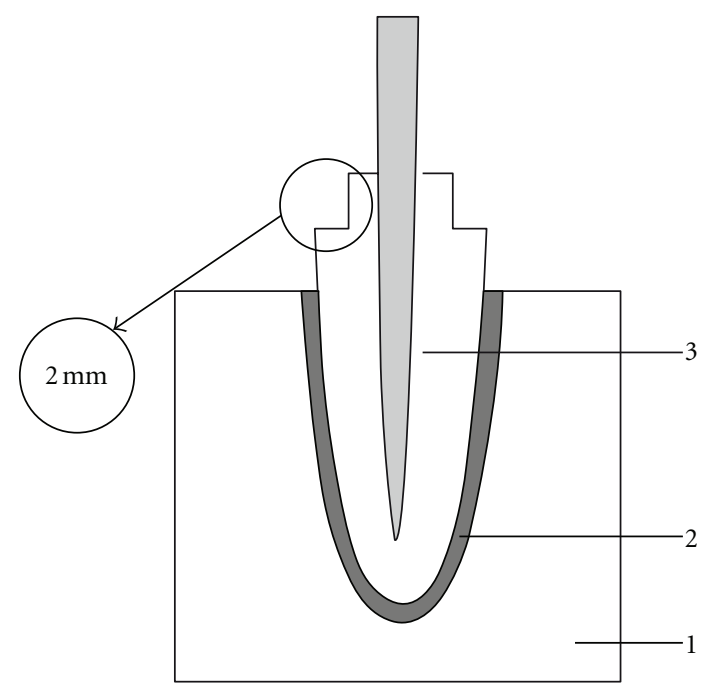

FIgURE 2: Ferrule effect. A circumferential collar of tooth structure at least $2 \mathrm{~mm}$ in height was preserved at the gingival aspect of the preparation.

a tooth should have a minimum amount $(2 \mathrm{~mm})$ of coronal structure above the cement-enamel junction (CEJ) to achieve a proper resistance $[43,44]$.

The results of the present study, in which to assess the mean fracture for each group the force was applied directly on the post head, in order to exclude other variables, have confirmed these observations.

About post insertion depth, it is known that with cast post and core system the post length was an important variable, because reducing post space can permit to save tooth structure positively affecting the tooth fracture resistance. Some authors [45] in a recent study designed to obtain a biofaithful model of the maxillary incisor system and to assess the effect of glass fiber post lengths using Finite Element Analysis showed that the overall system's

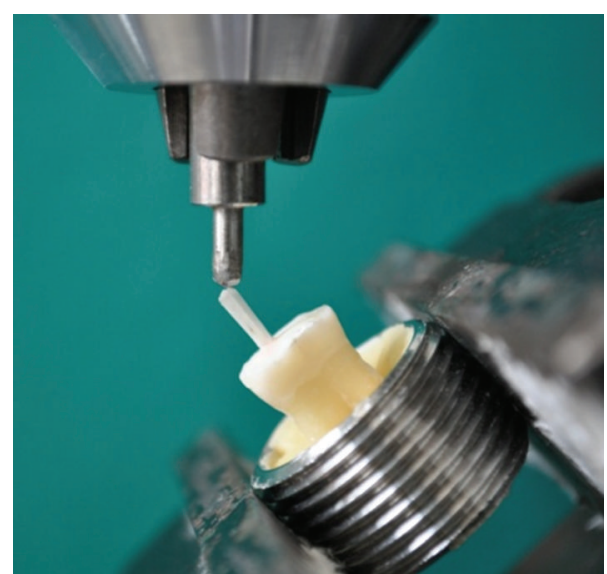

FIGURE 3: Example of a sample mounted on the loading machine and prepared for the fracture test. The tooth is oriented such as the load applied by means of the metallic stylus would have a 45 -degree direction.

strain pattern did not appear to be influenced by post length. This could lead to the conclusion that a post inserted more deeply could be more effective in a fiber post-supported rehabilitation, as the length of the post insertion has a significant effect on retention; the more apically the post is placed in the root, the more retentive is the system [46-48]. This consideration should not be overestimated in clinical practice. The adaptation of the canal shape to the post [49] and the overall length of the root should be in fact taken into consideration, because it has been reported that a residual apical filling of less than $3 \mathrm{~mm}$ may result in an unpredictable seal $[50,51]$.

From the results of the present study, a tendency of the more deeply inserted post to have higher values of resistance to fracture could be anyway observed, particularly in the no-ferrule groups. This might be connected with the use of tapered post, considering that a post inserted more deeply has a wider diameter at the breaking point. The use of a cylindrical shaped post could have minimized this differences, and this could be considered as a limit of the present study, even if Lang et al. [52] showed that if an excessive amount of tooth structure is removed and the natural geometry of the root canal is altered, this will have a destabilizing effect on root-filled teeth. For this reason in clinical practice the use of cylindrical-shaped post have been progressively abandoned and replaced with tapered post.

As general consideration, it should be noted that this in vitro study does not reproduce the exact clinical conditions, where lateral forces should be considered as well as axial forces and fatigue loading, ageing processes, alternate thermal stress, mechanical stress, wear, and water storage. In this in vitro study, in fact, lateral forces were applied with a $45^{\circ}$ angle between the post and the loading tip. Moreover, stress applied to the teeth and dental restorations is generally low and repetitive rather than being isolated and loading. However, because of a linear relationship between fatigue and static loading, the compressive static test also 
gives valuable information concerning load-bearing capacity $[53,54]$. Based on this statement, the results of this in vitro study showed that the ferrule effect positively affects the resistance to fracture of endodontically treated teeth restored with fiber posts. Conversely, post depth of insertion did not affect the resistance to fracture.

\section{Conclusion}

Within the limitation of this in vitro study, the statistical results showed that the ferrule effect in the endodontically treated teeth positively affects the fracture strength of the fiber post. Conversely, post depth insertion did not affect the resistance to fracture. It could be advisable in the rehabilitation of endodontically treated teeth preserve radicular tissue, reducing the postspace preparation, in order to improve the fracture strength of the post with a ferrule length of at least $2 \mathrm{~mm}$.

\section{References}

[1] S. Belli, A. Erdemir, and C. Yildirim, "Reinforcement effect of polyethylene fibre in root-filled teeth: comparison of two restoration techniques," International Endodontic Journal, vol. 39, no. 2, pp. 136-142, 2006.

[2] M. Trope and H. L. Ray, "Resistance to fracture of endodontically treated roots," Oral Surgery Oral Medicine and Oral Pathology, vol. 73, no. 1, pp. 99-102, 1992.

[3] E. S. Reeh, H. H. Messer, and W. H. Douglas, "Reduction in tooth stiffness as a result of endodontic and restorative procedures," Journal of Endodontics, vol. 15, no. 11, pp. 512$516,1989$.

[4] O. Pontius and J. W. Hutter, "Survival rate and fracture strength of incisors restored with different post and core systems and endodontically treated incisors without coronoradicular reinforcement," Journal of Endodontics, vol. 28, no. 10, pp. 710-715, 2002.

[5] F. H. O. Mitsui, G. M. Marchi, L. A. F. Pimento, and P. M. Ferraresi, "In vitro study of fracture resistance of bovine roots using different intraradicular post systems," Quintessence International, vol. 35, no. 8, pp. 612-616, 2004.

[6] M. Hayashi, Y. Takahashi, S. Imazato, and S. Ebisu, "Fracture resistance of pulpless teeth restored with post-cores and crowns," Dental Materials, vol. 22, no. 5, pp. 477-485, 2006.

[7] M. Ferrari, M. C. Cagidiaco, C. Goracci et al., "Long-term retrospective study of the clinical performance of fiber posts," The American Journal of Dentistry, vol. 20, no. 5, pp. 287-291, 2007.

[8] M. C. Cagidiaco, C. Goracci, F. Garcia-Godoy, and M. Ferrari, "Clinical studies of fiber posts: a literature review," International Journal of Prosthodontics, vol. 21, no. 4, pp. 328-336, 2008.

[9] M. Ferrari, A. Vichi, F. Mannocci, and P. M. Mason, "Retrospective study of the clinical performance of fiber posts," The American Journal of Dentistry, vol. 13, no. 2, pp. 9b-13b, 2000.

[10] M. Ferrari, M. C. Cagidiaco, S. Grandini, M. De Sanctis, and C. Goracci, "Post placement affects survival of endodontically treated premolars," Journal of Dental Research, vol. 86, no. 8, pp. 729-734, 2007.

[11] G. Heydecke, F. Butz, and J. R. Strub, "Fracture strength and survival rate of endodontically treated maxillary incisors with approximal cavities after restoration with different post and core systems: an in-vitro study," Journal of Dentistry, vol. 29, no. 6 , pp. 427-433, 2001.

[12] B. Akkayan and T. Gülmez, "Resistance to fracture of endodontically treated teeth restored with different post systems," Journal of Prosthetic Dentistry, vol. 87, no. 4, pp. 431437, 2002.

[13] A. Martínez-Insua, L. da Silva, B. Rilo, and U. Santana, "Comparison of the fracture resistances of pulpless teeth restored with a cast post and core or carbon-fiber post with a composite core," The Journal of Prosthetic Dentistry, vol. 80, no. 5, pp. 527-532, 1998.

[14] J. A. Sorensen and M. J. Engelman, "Ferrule design and fracture resistance of endodontically treated teeth," The Journal of Prosthetic Dentistry, vol. 63, no. 5, pp. 529-536, 1990.

[15] W. J. Libman and J. I. Nicholls, "Load fatigue of teeth restored with cast posts and cores and complete crowns," The International Journal of Prosthodontics, vol. 8, no. 2, pp. 155161, 1995.

[16] W. A. Saupe, A. H. Gluskin, and R. A. Radke, "A comparative study of fracture resistance between morphologic dowel and cores and a resin-reinforced dowel system in the intraradicular restoration of structurally compromised roots," Quintessence International, vol. 27, no. 7, pp. 483-491, 1996.

[17] R. W. Loney, W. E. Kotowicz, and G. C. Mcdowell, "Threedimensional photoelastic stress analysis of the ferrule effect in cast post and cores," The Journal of Prosthetic Dentistry, vol. 63, no. 5, pp. 506-512, 1990.

[18] N. Al-Hazaimeh and D. L. Gutteridge, "An in vitro study into the effect of the ferrule preparation on the fracture resistance of crowned teeth incorporating prefabricated post and composite core restorations," International Endodontic Journal, vol. 34, no. 1, pp. 40-46, 2001.

[19] C. Dobó-Nagy, T. Serbán, J. Szabó, G. Nagy, and M. Madléna, "A comparison of the shaping characteristics of two nickel-titanium endodontic hand instruments," International Endodontic Journal, vol. 35, no. 3, pp. 283-288, 2002.

[20] E. Asmussen, A. Peutzfeldt, and T. Heitmann, "Stiffness, elastic limit, and strength of newer types of endodontic posts," Journal of Dentistry, vol. 27, no. 4, pp. 275-278, 1999.

[21] A. D. Kececi, B. Ureyen Kaya, and N. Adanir, "Micro pushout bond strengths of four fiber-reinforced composite post systems and 2 luting materials," Oral Surgery, Oral Medicine, Oral Pathology, Oral Radiology and Endodontology, vol. 105, no. 1, pp. 121-128, 2008.

[22] S. Grandini, C. Goracci, F. Monticelli, F. R. Tay, and M. Ferrari, "Fatigue resistance and structural characteristics of fiber posts: three-point bending test and SEM evaluation," Dental Materials, vol. 21, no. 2, pp. 75-82, 2005.

[23] H. Lambjerg-Hansen and E. Asmussen, "Mechanical properties of endodontic posts," Journal of Oral Rehabilitation, vol. 24, no. 12, pp. 882-887, 1997.

[24] A. H. L. Tjan and S. B. Whang, "Resistance to root fracture of dowel channels with various thicknesses of buccal dentin walls," The Journal of Prosthetic Dentistry, vol. 53, no. 4, pp. 496-500, 1985.

[25] D. Dietschi, S. Ardu, A. Rossier-Gerber, and I. Krejci, "Adaptation of adhesive post and cores to dentin after in vitro occlusal loading: evaluation of post material influence," Journal of Adhesive Dentistry, vol. 8, no. 6, pp. 409-419, 2006.

[26] S. Bouillaguet, S. Troesch, J. C. Wataha, I. Krejci, J. M. Meyer, and D. H. Pashley, "Microtensile bond strength between adhesive cements and root canal dentin," Dental Materials, vol. 19, no. 3, pp. 199-205, 2003. 
[27] F. Mannocci, M. Sherriff, M. Ferrari, and T. F. Watson, "Microtensile bond strength and confocal microscopy of dental adhesives bonded to root canal dentin," The American Journal of Dentistry, vol. 14, no. 4, pp. 200-204, 2001.

[28] A. R. Helfer, S. Melnick, and H. Schilder, "Determination of the moisture content of vital and pulpless teeth," Oral Surgery, Oral Medicine, Oral Pathology, vol. 34, no. 4, pp. 661-670, 1972.

[29] J. L. Gutmann, "The dentin-root complex: anatomic and biologic considerations in restoring endodontically treated teeth," The Journal of Prosthetic Dentistry, vol. 67, no. 4, pp. 458-467, 1992.

[30] E. M. Rivera and M. Yamauchi, "Site comparisons of dentine collagen cross-links from extracted human teeth," Archives of Oral Biology, vol. 38, no. 7, pp. 541-546, 1993.

[31] E. S. Reeh, H. H. Messer, and W. H. Douglas, "Reduction in tooth stiffness as a result of endodontic and restorative procedures," Journal of Endodontics, vol. 15, no. 11, pp. 512$516,1989$.

[32] W. H. Douglas, "Methods to improve fracture resistance of teeth," in Proceedings of the International Symposium on Posterior Composite Resin Dental Restorative Materials, G. Vanherle and D. C. Smith, Eds., pp. 433-441, Peter Szulc Publishing, Utrecht, The Netherlands, 1985.

[33] J. Linn and H. H. Messer, "Effect of restorative procedures on the strength of endodontically treated molars," Journal of Endodontics, vol. 20, no. 10, pp. 479-485, 1994.

[34] P. Pantvisai and H. H. Messer, "Cuspal deflection in molars in relation to endodontic and restorative procedures," Journal of Endodontics, vol. 21, no. 2, pp. 57-61, 1995.

[35] P. R. Cathro, N. P. Chandler, and J. A. Hood, "Impact resistance of crowned endodontically treated central incisors with internal composite cores," Endodontics and Dental Traumatology, vol. 12, no. 3, pp. 124-128, 1996.

[36] H. Rosen, "Operative procedures on mutilated endodontically treated teeth," The Journal of Prosthetic Dentistry, vol. 11, no. 5, pp. 973-986, 1961.

[37] A. G. Gegauff, "Effect of crown lengthening and ferrule placement on static load failure of cemented cast post-cores and crowns," Journal of Prosthetic Dentistry, vol. 84, no. 2, pp. 169-179, 2000.

[38] J. R. Pereira, F. de Ornelas, P. C. Conti, and A. L. do Valle, "Effect of a crown ferrule on the fracture resistance of endodontically treated teeth restored with prefabricated posts," Journal of Prosthetic Dentistry, vol. 95, no. 1, pp. 50-54, 2006.

[39] J. R. Pereira, T. M. Neto, V. d. C. Porto, L. F. Pegoraro, and A. L. do Valle, "Influence of the remaining coronal structure on the resistance of teeth with intraradicular retainer," Brazilian Dental Journal, vol. 16, no. 3, pp. 197-201, 2005.

[40] P. R. Cathro, N. P. Chandler, and J. A. Hood, "Impact resistance of crowned endodontically treated central incisors with internal composite cores," Endodontics and Dental Traumatology, vol. 12, no. 3, pp. 124-128, 1996.

[41] F. Isidor, K. Brøndum, and G. Ravnholt, "The influence of post length and crown ferrule length on the resistance to cyclic loading of bovine teeth with prefabricated titanium posts," International Journal of Prosthodontics, vol. 12, no. 1, pp. 7982, 1999.

[42] R. W. Loney, W. E. Kotowicz, and G. C. Mcdowell, "Threedimensional photoelastic stress analysis of the ferrule effect in cast post and cores," The Journal of Prosthetic Dentistry, vol. 63, no. 5, pp. 506-512, 1990.
[43] K. C. Trabert and J. P. Cooney, "The endodontically treated tooth: restorative concepts and techniques," Dental Clinics of North America, vol. 28, no. 4, pp. 923-951, 1984.

[44] G. W. Wagnild and K. L. Mueller, "Restoration of the endodonticallytreated tooth," in Pathways of the Pulp, S. Cohen and R. C. Burns, Eds., pp. 765-795, Elsevier Saunders, St. Louis, Mo, USA, 8th edition, 2001.

[45] M. Ferrari, R. Sorrentino, F. Zarone, D. Apicella, R. Aversa, and A. Apicella, "Non-linear viscoelastic finite element analysis of the effect of the length of glass fiber posts on the biomechanical behaviour of directly restored incisors and surrounding alveolar bone," Dental Materials Journal, vol. 27, no. 4, pp. 485-498, 2008.

[46] J. P. Standlee, A. A. Caputo, and E. C. Hanson, "Retention of endodontic dowels: effects of cement, dowel length, diameter, and design," The Journal of Prosthetic Dentistry, vol. 39, no. 4, pp. 400-405, 1978.

[47] J. Nissan, Y. Dmitry, and D. Assif, "The use of reinforced composite resin cement as compensation for reduced post length," Journal of Prosthetic Dentistry, vol. 86, no. 3, pp. 304308, 2001.

[48] I. Nergiz, P. Schmage, M. Özcan, and U. Platzer, "Effect of length and diameter of tapered posts on the retention," Journal of Oral Rehabilitation, vol. 29, no. 1, pp. 28-34, 2002.

[49] M. K. Wu, A. R'oris, D. Barkis, and P. R. Wesselink, "Prevalence and extent of long oval canals in the apical third," Oral Surgery, Oral Medicine, Oral Pathology, Oral Radiology, and Endodontics, vol. 89, no. 6, pp. 739-743, 2000.

[50] L. Abramovitz, R. Lev, Z. Fuss, and Z. Metzger, “The unpredictability of seal after post space preparation: a fluid transport study," Journal of Endodontics, vol. 27, no. 4, pp. 292-295, 2001.

[51] M. K. Wu, Y. Pehlivan, E. G. Kontakiotis, and P. R. Wesselink, "Microleakage along apical root fillings and cemented posts," The Journal of Prosthetic Dentistry, vol. 79, no. 3, pp. 264-269, 1998.

[52] H. Lang, Y. Korkmaz, K. Schneider, and W. H. M. Raab, "Impact of endodontic treatments on the rigidity of the root," Journal of Dental Research, vol. 85, no. 4, pp. 364-368, 2006.

[53] S. Garoushi, L. V. J. Lassila, A. Tezvergil, and P. K. Vallittu, "Static and fatigue compression test for particulate filler composite resin with fiber-reinforced composite substructure," Dental Materials, vol. 23, no. 1, pp. 17-23, 2007.

[54] M. Naumann, G. Sterzenbach, and P. Pröschel, "Evaluation of load testing of postendodontic restorations in vitro: linear compressive loading, gradual cycling loading and chewing simulation," Journal of Biomedical Materials Research B, vol. 74, no. 2, pp. 829-834, 2005. 


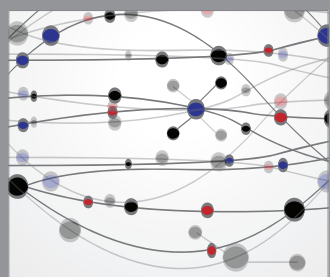

The Scientific World Journal
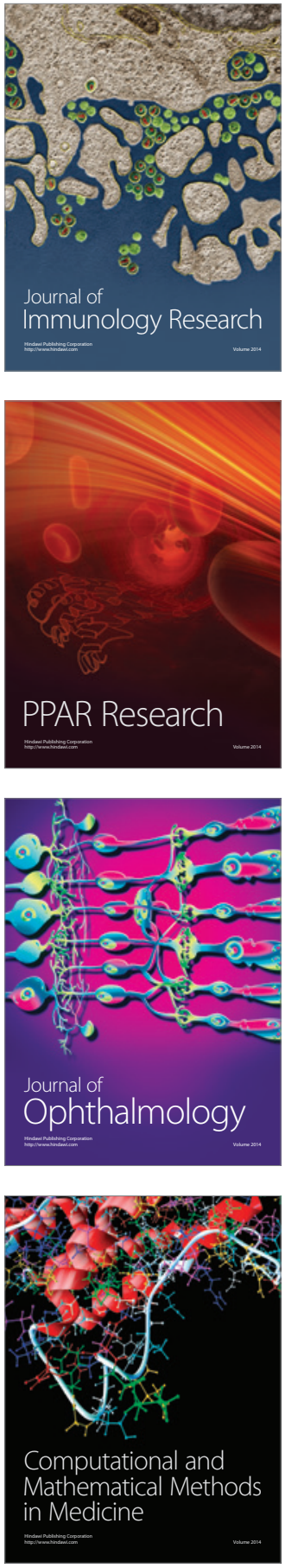

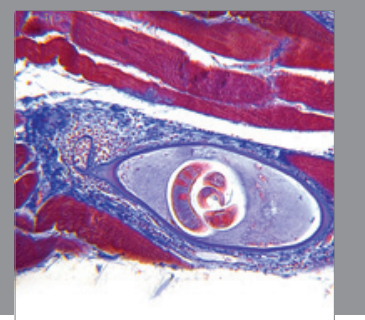

Gastroenterology

Research and Practice
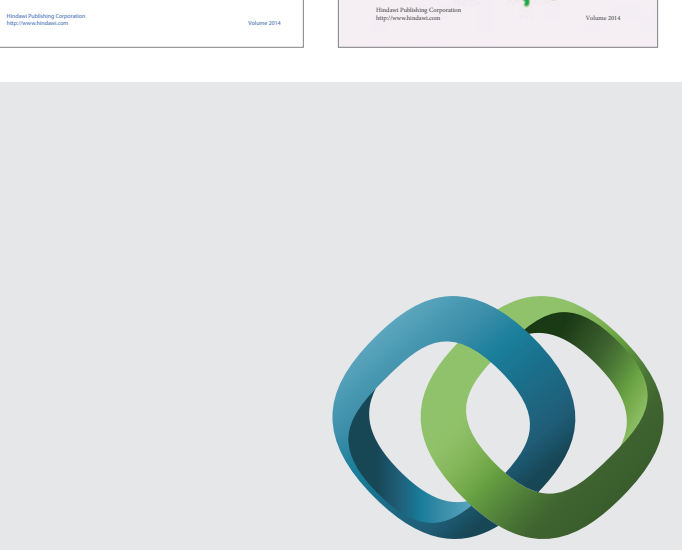

\section{Hindawi}

Submit your manuscripts at

http://www.hindawi.com
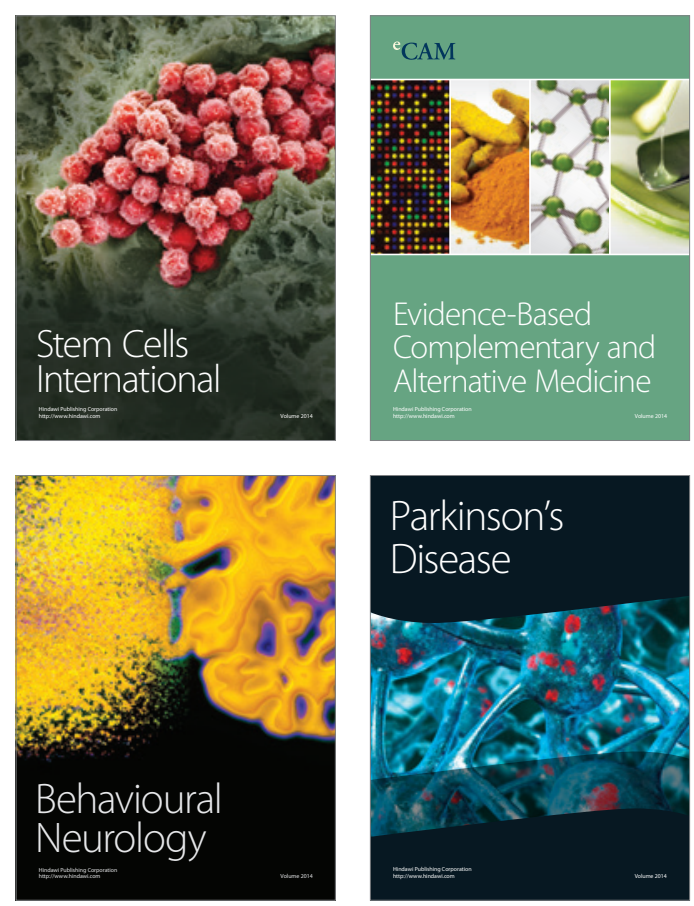

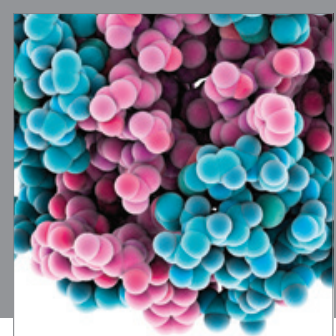

Journal of
Diabetes Research

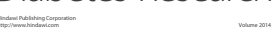

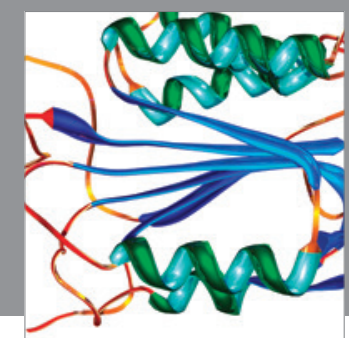

Disease Markers
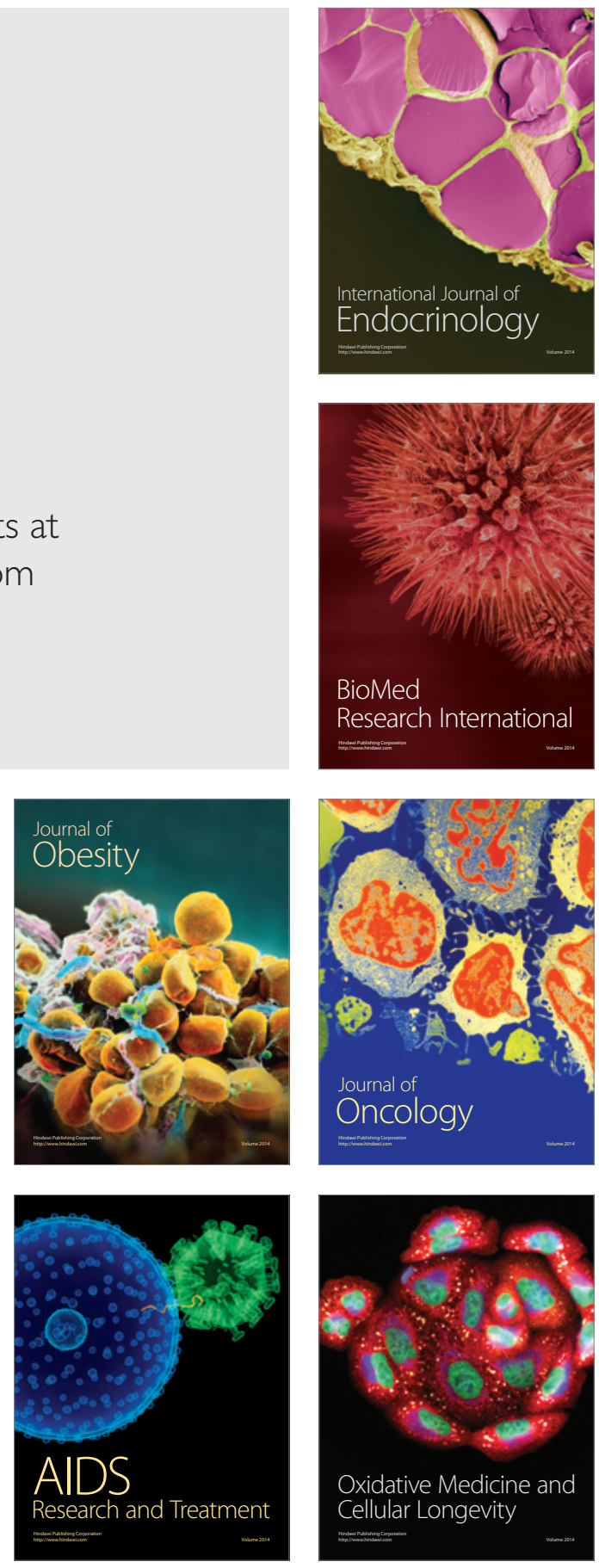